\title{
Optimization of the Personalized Service System of University Library Based on Internet of Things Technology
}

\author{
Yi Zhuang $(\mathbb{D}$ \\ Library, Shandong Women's University, Jinan 250300, China \\ Correspondence should be addressed to Yi Zhuang; 22012@sdwu.edu.cn
}

Received 1 March 2021; Revised 16 April 2021; Accepted 26 April 2021; Published 12 May 2021

Academic Editor: Wei Wang

Copyright (C) 2021 Yi Zhuang. This is an open access article distributed under the Creative Commons Attribution License, which permits unrestricted use, distribution, and reproduction in any medium, provided the original work is properly cited.

\begin{abstract}
In library applications, radio frequency indentification (RFID) technology, sensors, and wireless transmission networks have been applied to various services such as self-service checkout and return systems, electronic reader cards, intelligent bookshelves, intelligent monitoring of library premises, augmented reality (AR) interactive picture books, physical corridors, and seat reservations; in regional library alliances, real crossregional and cross-system alliance cooperation through IoT technology is also becoming increasingly important. Continuous information resource sharing is an important means to maximize the effectiveness of library information resources and meet the information needs of various users. The development of IoT technology opens new ideas and methods for information resource sharing in regional library alliances, effectively expanding the scope of information resource sharing and improving the efficiency of information resource sharing. This paper briefly presents the relationship, architecture, and key technologies of IoT technology and the definition, characteristics, and types of regional library consortium and content. Analysis of the characteristics and principles of regional library consortium information resource sharing is in the context of IoT and the corresponding studies on information sharing between regional library consortia at home and abroad. We also propose strategies to establish a specialized agency for information resource sharing, establish a sound investment mechanism for information resource sharing, ensure the security of information resource sharing of the regional library consortium, and increase the publicity and training capacity of information resource sharing of the regional library consortium.
\end{abstract}

\section{Introduction}

With the rapid development of the Internet, the earth has been transformed into a global village. Information technology has penetrated into all walks of life and all fields of the world [1]. People cannot live and work without the Internet. However, under Moore's law, i.e., the information society will produce a revolution every fifteen years. The development of the Internet has hit a bottleneck and is suffering from various challenges while facing many opportunities. The Internet of Things (IoT) is an "internet of things" based on the traditional Internet, using technologies such as RFID and wireless sensor networks to build an "internet of things" that connects things and senses each other [2]. The birth of the Internet of Things is the inevitable product and wisdom crystallization of the development of the Internet to a certain stage of $W$ and economic and social development and is a new technological revolution in the field of information technology. With the progress of the times, the number of books is growing exponentially. At the same time, with the improvement of people's ideological awareness, the borrowing volume of books is also increasing [3]. As an important carrier of books, the difficulty of book management in libraries has increased, and the traditional manual management method is no longer suitable for the needs of modern book management. How to improve the accuracy, security, and efficiency of book management at a lower cost is the most urgent task of many university libraries. Books are important in library book management because they are valuable, easily damaged, not lost, and not renewable [4].

After IBM put forward the concept of "Smart Earth" in 2008, smart transportation, smart city, smart medical care, smart education, and other related topics have emerged and received wide attention. In recent years, the concepts of 


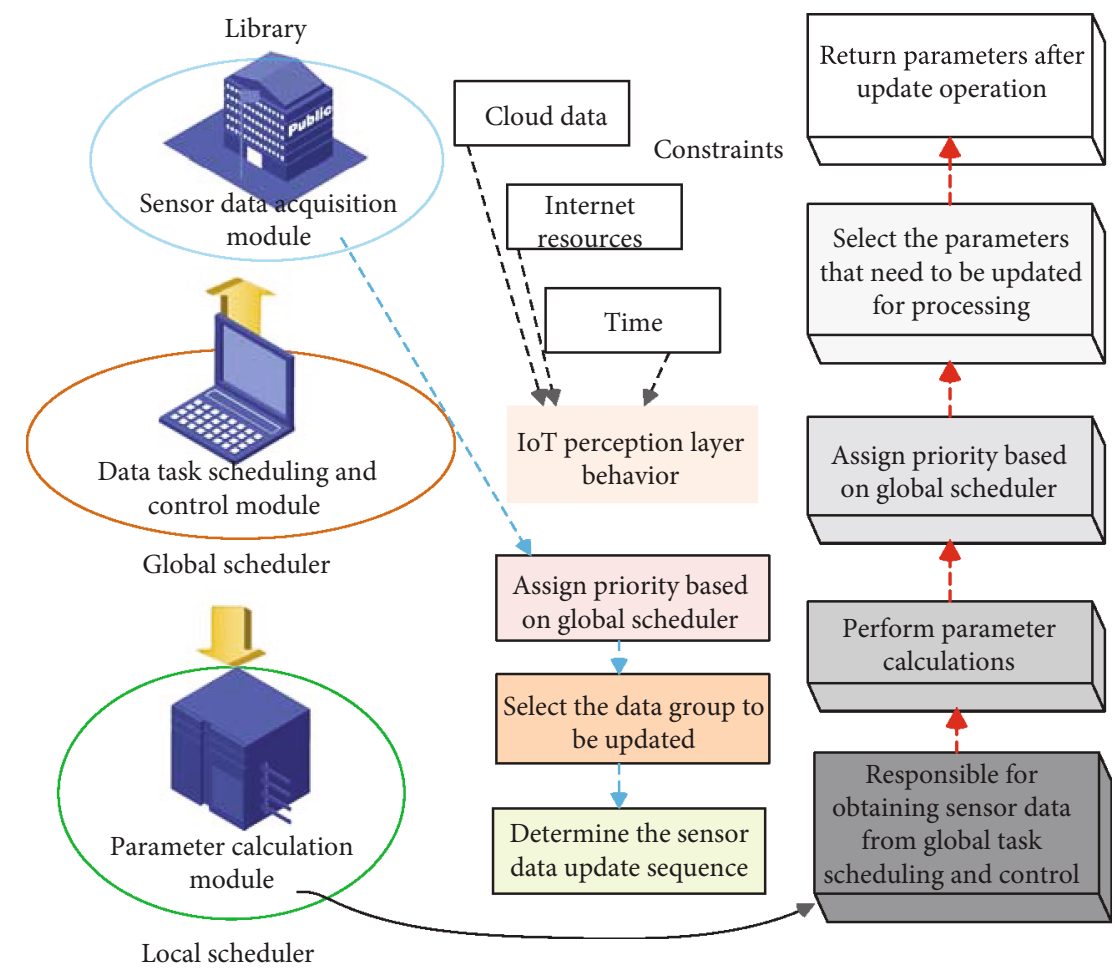

FIGURE 1: Intelligent library management.

"smart campus" and "smart learning" in domestic universities have also been proposed, and the research of smart library, as an integral part of smart campus, has become more and more the focus of modern library research, as shown in Figure 1. Under the era of wisdom, the essential characteristics of public welfare services cannot be changed, and the position of its main functions and related functions cannot be reversed [5]. However, university libraries must highlight "wisdom" in their future construction goals and services. With the deepening of Internet, cloud computing, and big data technology, libraries are developing in the direction of wisdom libraries. The construction and innovation of university wisdom libraries will inject new vitality, provide new ideas and expand new space for the new period of university libraries, and provide practical experience and models that can be referred to for the role innovation and function transformation of university libraries [6]. In the background of the intelligent era, the proposal of "intelligent library" is promoting the transformation of university libraries from traditional lending to intelligent service, from paper-based to digital resources-based, from centralized to distributed, from passive to active, from common to individual, and from stereotyped manual to flexible and intelligent, and the service of university libraries has gradually realized the transition from traditional type to digital and mobile libraries. The services of university libraries have gradually realized the leap from traditional libraries to digital and mobile libraries [7]. Knowledge diffusion has put forward higher-level requirements on the way of serving information resources in university libraries, and the needs of readers and users have shifted from simply searching for information resources to more efficient access to information resources that meet their diverse new needs [8-11]. In the age of the Internet, each information user is both a creator and a provider of information, and saving time and cost is also a service that patrons urgently need. Smart libraries aim to help every reader user find the library information resources they want quickly, efficiently, and accurately, so that users can take what they need, and libraries can take their responsibilities, optimize the work of the entire library system, effectively shorten the time of information processing, improve the diversity of information resources, and realize smart services [12].

The future development goal and need of university libraries are the integration of digital resources and integration of user services, providing readers and users with a convenient, fast, and prudent way of service delivery. From the traditional physical library to the digital library, the digital library to the complex library, and then to a higher-level intelligent library, no matter how technology evolves and changes, the library principles of "people-oriented," "reading-centered," and "service-oriented" still apply. Regardless of how technology advances and changes, the basic concepts of "people-oriented," "reader-centered," and "service" libraries remain unchanged. Therefore, it has been the responsibility of libraries to change from traditional "passive stereotypical service" to active "active intelligent service." This paper introduces the concepts and key supporting technologies of information construction of the recommendation system of the wisdom library, including wisdom library, recommendation system, and mainstream algorithm of the recommendation system, briefly compares and analyzes the advantages and disadvantages of common recommendation algorithms of the recommendation system, and finally elaborates the wisdom library service model based on the wisdom 
recommendation system, which provides the theoretical basis for the construction of the wisdom library service model. Finally, we provide the theoretical basis for the construction of the service model of smart library.

\section{Related Work}

Scholars have mainly studied the definition, characteristics, service principles, service roles, service means, service targets, or service evaluation of smart libraries. At the conference on "Human-Computer Interaction Mobile Devices" in 2003, Aittola of Oulu University Library in Finland proposed that "Smart Library" refers to a mobile library that can break the limitations of location and space and be perceived by people and actively find the users' needs for them. Aittola, from the University of Oulu Library in Finland, suggested that a "Smart Library" is a mobile library that can break the limitations of location and space and be perceived by people, actively finding the library information resources for the users. In February 2010, the Smart Libraries Newsletter, a publication of the American Library Association (ALA), was launched with the title "Smart Libraries Through Technology." In February 2010, the Smart Libraries Newsletter, a publication of the American Library Association (ALA), featured a column entitled "Smart Libraries Through Technology", which was devoted to the latest information and progress in the development of smart library technology. The researchers examine the status and value of intelligent agent technology in the context of the goal of smart libraries. The researchers envision a model for smart libraries that can maximize the effectiveness of library services by supporting the integration and analysis of data and information resources. The researcher believes that in the context of the information age, the ability to adapt to the changing environment and thus provide the services required by the general public is the primary and core value for the existence and survival of libraries. Scholars have used questionnaires and other methods to study the digital resource use and learning behavior of library patrons, suggesting the strengthening of cooperative and informal library functions and summarizing and analyzing the smart library information service model from the perspective of patron users [13].

Researchers have proposed that smart libraries should have two service models, namely, the market model and the evaluation model. The marketplace model has obviousness selection characteristics and is based on effective communication between librarians and patrons; the assessment model has potential evaluation characteristics and is a description of the current state of patrons and prediction of their future choices [14]. The researchers explored various recommender systems in terms of characteristics and technical potential and described the application of various predictive tools in recommender technology as a guide for research and practice in the field of recommendation. Researchers proposed new algorithms for recommender systems based on timedecaying weights and matrix clustering that can better solve the data sparsity problem and better respond to the variable interests of users [15]. Researchers, on the other hand, have opened up new perspectives in the recommendation system development research, supporting the inclusion of user participation in the development and design process of recommendation systems to better tap into users' unique preferences. In recent years, foreign scholars have been studying library consortia since the 1970s, when they first mentioned the definition of "library consortia" and analyzed the development of university libraries in the United States, emphasizing the role of library consortia in library development. The previous results focus on the creation and maintenance of information resources by various institutions on the Internet of Things, and through interregional and intersectoral links, truly realize the common construction and distribution of resources, and provide readers with rapid and convenient access to digital resources.

Researchers mentioned that a library consortium is a collaboration of two and more libraries, a new consortium bound by a mutually agreed agreement for the purpose of sharing resources, reducing costs, and mutual benefits. Based on the adherence to the agreements among the alliance members formalizing the organization of the alliance at present, library association organizations have violated the tangible boundaries of libraries in the past, and the hierarchical distinction of libraries is not very different, and the members of alliance libraries enjoy rights and obligations equally. With each library's collection with its own characteristics and focus, each member library has a relatively deep understanding of common construction and sharing, for example, the United States has solved the logistics and distribution problems of interlibrary loan in the cooperation process of library union and truly realized the deep integration of resource sharing. Foreign research on information resource sharing has focused on library cooperation, library collections, library networks, and library consortia [16].

The Duchy Library of Weimar in Germany established an interlibrary loan relationship with the University Library of Jena in the late 18th century, which was one of the earliest models for libraries to share information resources. First proposed by Melvil Dewey in 1886, library cooperation, also known as interlibrary cooperation, has emerged as a library resource sharing activity and is often found in libraryrelated literature and library conferences. In order to achieve resource sharing, member libraries should develop collections among themselves and develop various services based on the collections, and cooperative collections should be a way to reduce duplicate acquisitions and achieve economical acquisitions. Using interviews and document delivery tests, the researchers interviewed librarians in 15 university libraries to investigate their perceptions of inappropriate services. It was concluded that resource sharing would not operate in an equitable manner if the majority of users' requests were directed to only a small portion of the university libraries in Taiwan [17]. Inadequate library collections in any region or country will not allow resource sharing. The researchers pointed out the participation of the library of the Institute of Advertising and Marketing of Rio de Janeiro and the library of Petro Acutepolis, a member country of the CBIES/RJ Resource Sharing Association of the State of Rio de Janeiro, Brazil, in the consortium. The main results are scientific and technical knowledge sharing, collaborative 
access to software and databases, development of an online collaborative catalog series, and information retrieval and access facilities. This experience has shown that library consortia are effective tools for information resource sharing and contribute to the quality of academic education.

\section{Basic Theory of Library Information Resource Sharing in the Context of Internet of Things}

3.1. Internet of Things Technologies. The huge increase in online information has led users into a sea of information explosion, and data overload has caused information scarcity, resulting in the inability of users to obtain information that is truly useful to them. The Internet of Things is a series of science and technology, using sensor devices to connect objects and computer terminals, through computer control to achieve automatic and intelligent objects, and to achieve the goods and goods information by the Internet to pass and express, is the Internet outward extension and expansion of the network, and is the user side of the exchange of information and communication between goods and good network. The architecture of IoT can be divided into three parts: sensing layer, network layer, and application layer, as shown in Figure 2.

The sensing layer is mainly sensed by various sensors and then transformed into signals to be transmitted, such as temperature and humidity sensors, position sensors, and acoustic sensors. The sensing layer is mainly used to collect the physical world and information, including physical quantities, signs, audio, and video. The role of the perception layer is equivalent to the role of human sensory organs to the human body system, by collecting information from the perceived external environment to identify objects and perceive physical-related information. The network layer is the communication module that transmits signals from the conversion of the sensory layer to each other through Internet technology, which mainly refers to the current communication technology and terminal technology that provides communication capability for terminals in various industries. The network layer is equivalent to the human nervous system, capable of transmitting the sensed information without barriers, with high reliability and security, and requires the mutual integration of sensor networks and mobile communication technologies and Internet technologies.

$\mathrm{M} 2 \mathrm{M}$ is the transfer of data transmitted by sensors from one end machine to another, i.e., enabling machine-tomachine conversations in the Internet of Things. M2M, one of the core technologies of the Internet of Things, is now a prevalent form of IoT application that enables all machines and devices to be equipped with communication and networking capabilities, allowing for a truly seamless interface between machines and people and systems. Cloud computing technology is an Internet-based computing method through which some shared related hardware resources and network information technology are made available to other computers according to demand and is a product of the convergence of computer development needs. It is the core of the realization of the Internet of Things, using the cloud computing model, which provides a dynamic scalable virtualized resources of the computing model. It also has super storage capacity, which is also equivalent to the central nerve of the "brain" of IoT, with computing and storage capacity. IoT sensors and Internet operators interact with information through network lines and computer terminals to provide data to the cloud and receive technical services from the cloud.

\subsection{Regional Library Service System Based on Internet of} Things. Library consortia have been a hot topic of research in library science at home and abroad, reaching a peak in the 1990s and gradually stabilizing. The widely accepted definition is that a library consortium is a consortium of libraries in a certain range organized for the purpose of resource sharing and mutual benefit and governed by mutually agreed agreements and contracts. The regional library consortium is not only limited to the cooperation between libraries but also the cooperation with all sectors of the society within the geographical area that can be called a consortium, which is based on a mutually agreed agreement or contract, and is a cooperation subject to mutual constraints. This kind of cooperation can be interlibrary cooperation, digital resource sharing, library book loan and return, cooperation in purchasing databases, joint development of special databases, lecture alliance, training alliance, publicity activities alliance, etc., which are important initiatives for the common development of libraries and all sectors. The early library alliances mainly cooperated with libraries of the same system, and the content of the alliances was also based on basic business, with little communication with the outside world, little influence in the society, and low social status. Nowadays, the alliance tends to be more and more a big partnership across systems, industries, regions, and disciplines and is oriented to the society, with links and cooperation between groups such as government departments, research institutes, commercial companies, educational institutions, and new media industries, as shown in Figure 3. This alliance is the integration of libraries with talents, technologies, and social resources from all walks of life under IoT technology, which can effectively improve user satisfaction, social influence, and social status.

The early library alliances were mostly cooperative in terms of joint cataloging of literature, interlibrary loan, and coordination of book division in the collection. Modern library alliances under Internet and IoT technologies, on the basis of the original cooperation, also cooperate in areas such as librarian training, technical seminars, expert lectures, celebrity painting and calligraphy exhibitions, reference consultation, resource procurement, digital resource coconstruction and sharing, and smart library construction. Using more institutions, the form results focused much on the controlling of the information and crossconstruction. However, a hierarchical distinction of libraries has not yet been applied in the libraries. Based on this consideration, members should consider much on the digital resources compliance with the agreements among alliance members. Library consortium is an alliance between libraries and other groups based on 


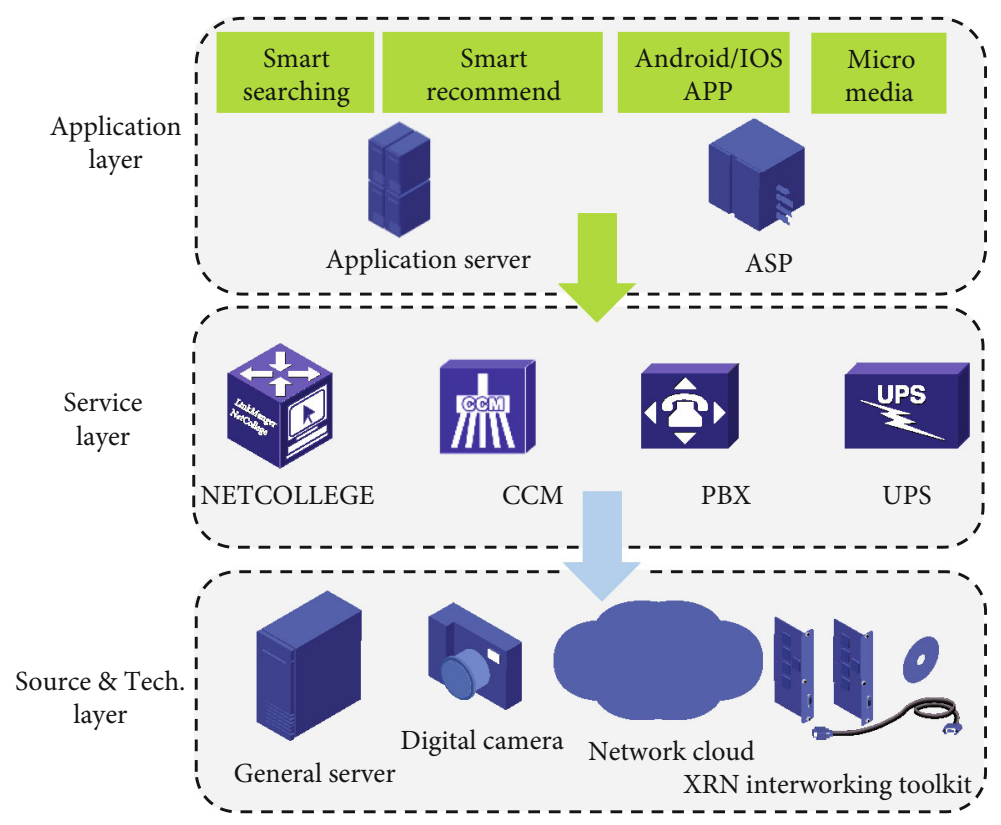

FIGURE 2: Internet of things architecture.

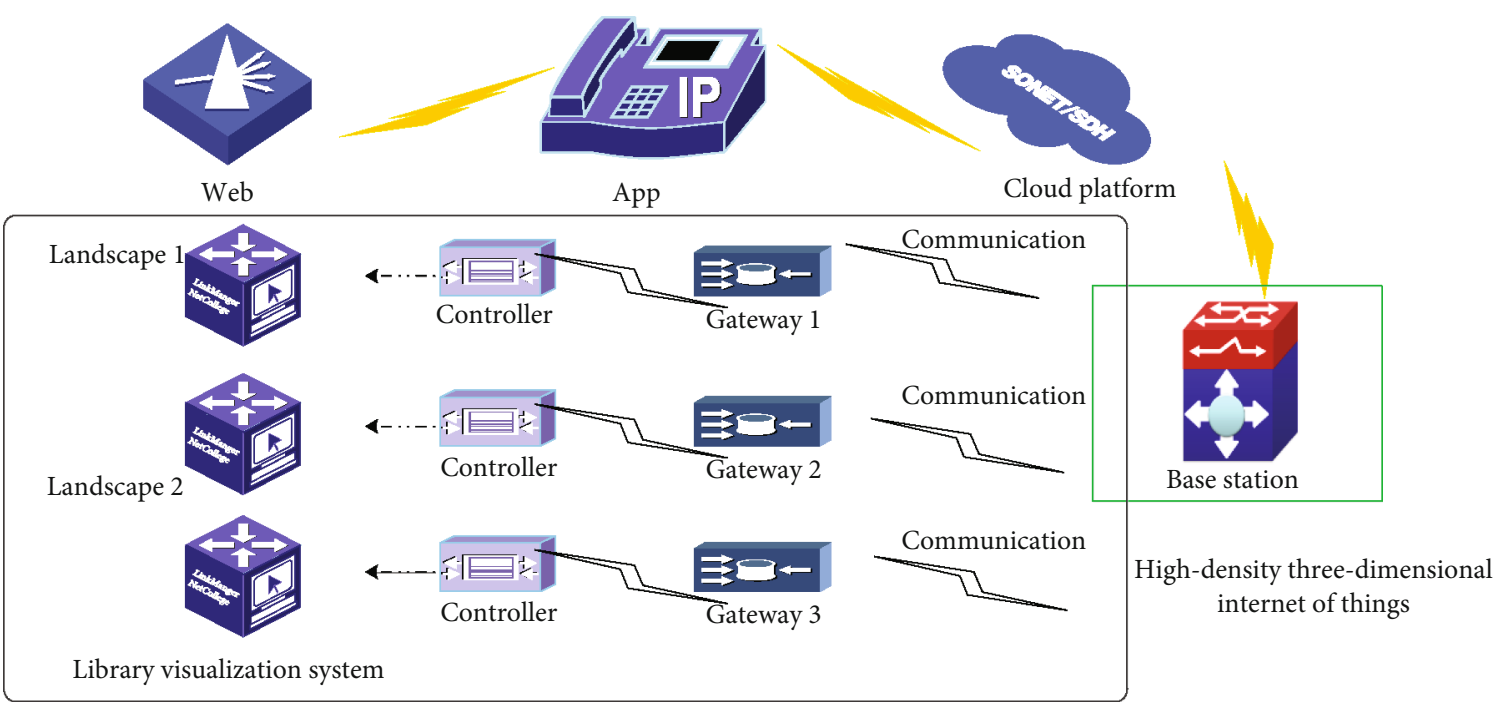

Figure 3: Regional library consortium service system.

cooperative relationship, and all member libraries join voluntarily and are established with the will of common building and sharing, mutual benefit, and mutual assistance. At the beginning of establishment, standardized constitution and system will be formulated through common discussion, and fixed full-time staff will be established for management, and if any unit fails to comply with or violates the rules and regulations, it will be punished or expelled. If flexible management is required for work in the operation process, member libraries should also actively cooperate in the management and communication work such as institutional integration, benefit and risk distribution, and business process reorganization. There is a wide variety of types of library alliances, and there is no more standardized and unified criteria to compare from some aspects that are to divide the same kinds of alliances into one type. Each type of alliance is an alliance formed by member libraries on the premise of three major elements: a foundation of trust, a consensus of culture, and an effective monitoring system for the purpose of sharing resources, reciprocal benefits, and promoting the overall development of libraries. The United States is the fastest growing country in terms of the number of library consortia and the number of types of development crisscrossing the country.

For each reader $u$ belonging to the nearest candidate neighbor $\mathrm{Mc}$, the set of books borrowed by the reader and the target reader in a certain statistical time period is found from the OPAC system library and is represented by the set $U_{n}$. Based on Mc and $U_{n}$, a user-item matrix is created, denoted by $A(m, n)$, which contains the set $V=\left(u_{1}, u_{2}, \cdots\right.$ $\left.u_{m}\right)$ of $m$ target readers and the set $I=\left(i_{1}, i_{2}, \cdots \cdots i_{n}\right)$ of $n$ book information resources, in). The rating of reader $u$ for 
book $i$ is represented by the matrix element $R_{u i}$. If reader $u$ has no borrowing behavior for book $i$ within a certain time statistic, $R_{u i}=0$. If reader $u$ has borrowing behavior within the statistic time period, the value of $R_{u i}$ is determined based on the borrowing time because the length of borrowing time reflects the long-term preference of readers to a certain extent, which is calculated as follows: let the sequence of books borrowed by reader $u$ within a certain statistic time be (item 1 , item $2, \ldots$, item $i, \ldots$, item $n$ ), the corresponding borrowing time sequence is $\left(t_{1}, t_{2}, \ldots t_{i}, \ldots, t_{n}\right)$, and the starting time of the statistical period is time which is Tmin, the cut-off time is Tmax, and then the reader $u$ for the book item iis the rating value calculation, such as the formula

$$
Q_{o}=\frac{\sum_{i=0}^{n} t_{i}+T_{\min }}{T_{\max }} .
$$

Based on the user-item matrix, the top- $N$ readers who are the closest and most similar to the target readers are calculated as the set of nearest neighbors of the target readers by modifying the formula of cosine similarity. The calculation formula is as follows:

$$
\max \left(Q_{o}, Q i\right)=\frac{\sum_{i=0}^{n} \sum_{i=0}^{n}\left(t_{i}+T_{\min }\right)_{i j}}{\sqrt{\left(t_{i}+T_{\max }\right)_{i j}}},
$$

where $\max \left(Q_{o}, Q_{i}\right)$ denotes the similarity between reader $u_{1}$ and reader $u_{2}$ tables the books jointly rated by reader $u_{1}$ and $u_{2}, R_{u 1, c}$, denotes the rating of reader $u_{1}$ on book $c$, and $u_{2}$ denotes the average rating of reader $u_{1}$ and reader $u_{2}$ on the books.

Based on the rating data of book resources by the nearest neighbors of the target readers, the interest preference of the target readers for books $P_{u, i}$ can be predicted. Then, by setting the number of recommended books, or the threshold of readers' interest preference, book resource recommendations are generated for the target readers. Using this formula based on the weighted average of item means, the rating prediction of book resources is made within the nearest neighbor set of the target readers. Let the nearest neighbor set be $U$ and be the interest preference of $P_{u, i}$ target reader $u$ for book $i$. Then, $P_{u, i}$ can be calculated using the rating data of the target reader's nearest neighbor set for book $i$. The formula is as follows.

$$
Q_{n, i}=\frac{R_{q}}{\sum_{j=0}^{m} \sum_{i=0}^{n} \operatorname{siru}\left(n_{i}, n_{j}\right)} .
$$

3.3. Personalized Service Optimization in the Context of IoT. The intelligent library service model based on the recommendation system studied in this paper is centered on serving readers and users and focuses on relying on information technology to provide personalized and intelligent services for libraries. The overall block diagram of the intelligent library service model for universities is shown in Figure 4. Intelligent search is the premise and foundation of intelligent recommendation. Retrieval is the first step for users to obtain information, and intelligent retrieval in university libraries aims to enable readers to retrieve the required information more quickly, accurately, efficiently, and in an orderly manner. Compared with traditional retrieval, intelligent retrieval can record and analyze users' retrieval behavior, identify users' clear or potential demand preferences, and present users with the most relevant retrieval results; on the other hand, it can automatically correct retrieval strategies through users' feedback or evaluation of retrieval results, so that users can get the resource information closest to their needs and improve users' intelligent experience in retrieval. While traditional information retrieval is based on keywords or similarity-based retrieval, the basic concept of wisdom retrieval is to realize the established needs of established users. On the basis of traditional search, smart search intelligently filters out part of the information that may be invalid for users and helps readers locate the resource information they need more quickly and precisely. Not every user logs in to reader services every time they visit a library website, and most users simply try to quickly retrieve the books they need. Therefore, many users usually prefer the most time- and energy-efficient behavior and method to achieve their search purpose. Through intelligent search, it can make the search results more targeted and contain links directly to the final result page, thus not only can help users avoid the blindness of book search, shorten the time of book search and reduce the difficulty of search but also improve the efficiency of user search and enhance the accuracy and reliability of book search results.

Based on its own specificity and research needs, this paper synthesizes the survey results and classifies the recommendation services of university libraries into two categories, namely, personalized and nonpersonalized recommendation services. Personalized recommendation refers to the ability to provide users with personalized and intelligent recommendations by analyzing and mining user behavior information according to certain techniques and methods based on the characteristics and needs of different users. It can predict users' preferences based on their characteristics and needs. Such as guess your favorite recommendation services, the recommended content has special, targeted, predictive. Intuitively, from the perspective of recommendation results, different users get different recommendation results (which can be similar). Nonpersonalized recommendations can only meet the general needs of general users, but not for readers with different backgrounds, different purposes, and different time periods. Intuitively, from the viewpoint of recommendation results, different users get the same and nondifferentiated recommendation results.

Nonpersonalized recommendations are usually in the form of a simple page, presenting all the recommended information directly to all users, without targeting, such as new books to the library, lending ranking and other recommendations, and the recommended content is universal and general. Nonpersonalized recommendation is also subdivided into dynamic nonpersonalized recommendation and static nonpersonalized recommendation (hereinafter, referred to as 


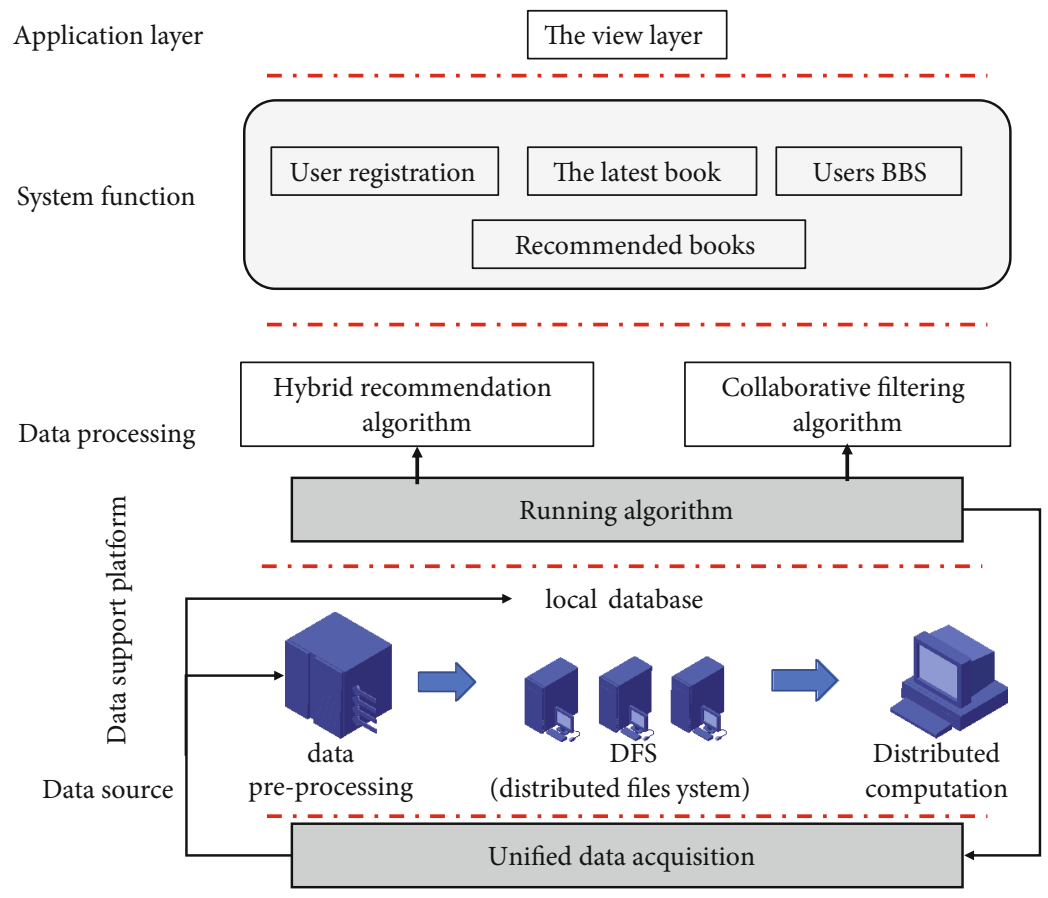

FIgURE 4: Overall block diagram of the personalized service model.

dynamic recommendation and static recommendation). Dynamic recommendation refers to the recommendation that different users get the same recommendation, but need to be realized by certain technology or algorithm, or a threshold as a scale, or a time period as a boundary, to dynamically display the recommended content, such as popular lending, lending ranking, and other recommendations. Static recommendation means that the librarians present the recommendation results to the users in a static page through the editing operation of the backend website. For example, the new book notice is presented to all readers in a simple static page, while the popular borrowing is based on certain dynamic data through statistical analysis and other techniques to come up with the recommendation results.

Of the 109 university libraries surveyed, all libraries offered some portion of the nonpersonalized service, as shown in Figure 5, representing $100 \%$ of the libraries surveyed. Sixty-nine libraries, or $63 \%$ of the libraries surveyed, provide a portion of the personalized recommendation service. Among the static recommendations, about $96 \%$ of the libraries provide new book announcement recommendation service, which shows that universities pay more attention to publicizing and promoting new books that come to their libraries. About $28 \%$ of the libraries in the surveyed universities provide the recommendation service for librarians, teachers, and students, about 19\% of the libraries provide the recommendation service for course reference books, and about $10 \%$ of the libraries provide the recommendation service for classic books, which is the lowest percentage. In addition, $79 \%$ of the surveyed university libraries provide recommendation services to readers in the form of resource links, which, by providing a link related to searching for books, point to reading platforms such as Douban and Google. Among dynamic recommendations, about $62 \%$ of all sur-

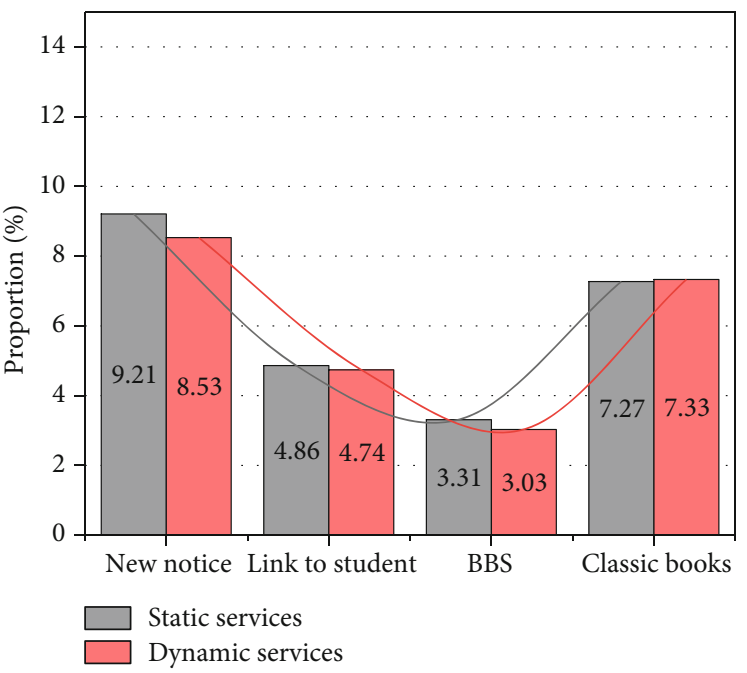

FIGURe 5: Static and dynamic personalization services.

veyed colleges and universities provide popular search recommendation service, which is the highest percentage, about $58 \%$ of colleges and universities provide popular borrowing as a recommendation service method, about $57 \%$ of colleges and universities provide popular collection recommendation, about $55 \%$ of colleges and universities provide using popular evaluation service, about $46 \%$ of colleges and universities provide popular recommendation method, and about $34 \%$ of the colleges and universities provided the lowest percentage of recommendation methods of borrowing ranking. It is possible that there is a crossover between the various recommendation methods, and institutions have chosen only one or more of them. 


\section{System Optimization Test}

There are many valuable or potentially valuable knowledge and rules in user behavior information. Through the analysis of users' retrieval behavior and implied association behavior, the intelligent retrieval service can use data mining, association rules, and other technologies to provide recommendation services to mass users who are not logged in at the corresponding position on the relevant detailed information page, recommending the same, similar, or related books they retrieve or browse, so as to help users find the books they need more quickly and accurately, and thus reducing the book search service is a kind of a nonsense search service. The essence of intelligent retrieval is a kind of impersonal recommendation, which is a practical application of data mining analysis technology in information resource retrieval processing and belongs to a kind of analysis and mining activity for information resources in the network.

At present, OPAC online public search catalog is the main network entrance for university libraries to search library resources, and it is the most important platform and window for readers to query and browse books with libraries. The design and implementation of its functions have the most direct impact on the quality of library services and material utilization. Therefore, the development of intelligent search technology relies on the OPAC system to a considerable extent. Users retrieve library resource information through OPAC search engine, and user query log information can be formed in the backend of the library website to describe the user's search behavior. The intelligent retrieval system can construct a user behavior model, and on the basis of querying and analyzing user behavior logs, mine potential information of user retrieval behavior then predict the retrieval results that users may visit or prefer and intelligently select and recommend information resources that are close to users' interests or behaviors. By correlating user retrieval with retrieval results and making implicit knowledge of behavior explicit for retrieval results, the intelligent retrieval service recommends hidden books to users, which can make users improve their accuracy in retrieval while feeling novel and diverse, as shown in Figure 6, so that the knowledgefilled correlation or similarity intelligent retrieval will be more tempting to users.

Smart retrieval is the first step to provide users with smart services, mainly serving general public users and belonging to a rough refinement. Smart recommendation is similar to the information retrieval system represented by search engine, but with more emphasis on personalized, diversified, and novel recommendation results. Search is to know exactly what you are looking for, but search is no longer a solution under information overload. The recommendation system is a "push" and "pull" interaction, that is, to recommend information resources to users, while providing and displaying information resources to users to help them choose information. Compared with the intelligent search engine which simply lists the search results on the basis of certain filtering, the intelligent recommendation system can study the behavioral preferences of readers, establish the reader user model, and discover the interest points of readers, so as to meet the

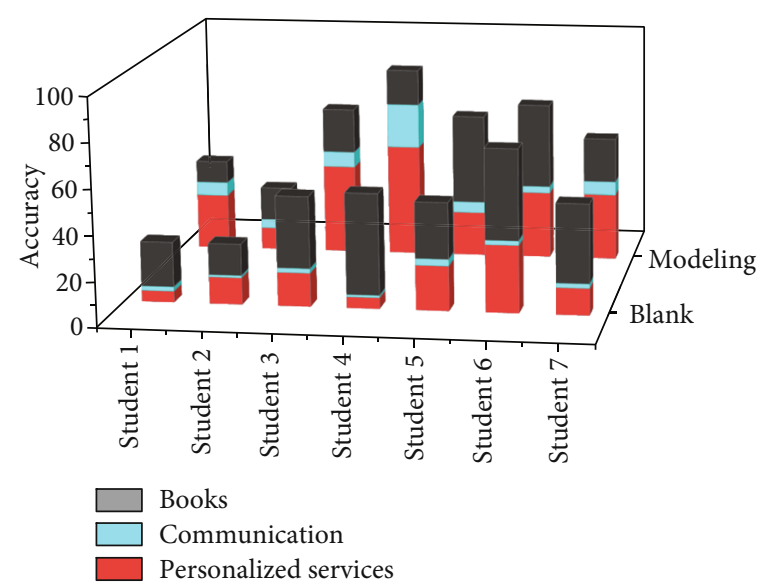

Figure 6: Personalized push accuracy.

diversified new demands of readers for information resources, improve the utilization rate of library resources, and enhance the intelligent processing ability of knowledge and information. With the core of integrating digital information resources to serve readers, the main task of the wisdom recommendation system is to link users and information from the passive of query to the active of recommendation, with humanized, personalized, and socialized features, helping users find valuable information and also allowing potentially valuable information to be presented to users, in order to achieve a win-win situation for knowledge producers and knowledge consumers. In addition, a highquality wisdom recommendation system can generate wisdom recommendations to reader users on the one hand, and on the other hand, it can build a close connection with reader users, so that reader users can form a dependence on wisdom recommendations.

The information service system enables a more personalized recommendation function. Firstly, it enables a simple subject book push service based on readers' interest information. To meet the needs of readers, the information service system collects RSS feeds of various Chinese and foreign language journals and allows readers to customize the journal resources they are interested in, and after successful customization, the titles of relevant journals can be pushed to readers regularly to keep users abreast of the latest situation of journals. The existing OPAC system of university libraries can no longer meet the increasingly diversified information needs of patrons, let alone provide intelligent library information resource recommendation services. Although the OPAC system also provides services such as popular lending and new book recommendation, these basic recommendation services cannot differentiate between different readers and users, as shown in Figure 7, but provide the same book recommendation for all readers and users. The information service system, on the other hand, can use the information of each reader's personal professional background to provide differentiated recommendation services such as popular borrowing, compared with the simple recommendation attached to the OPAC system. Since university faculty and students have relatively stable disciplinary backgrounds, which are strongly related to their faculty backgrounds, the information service 


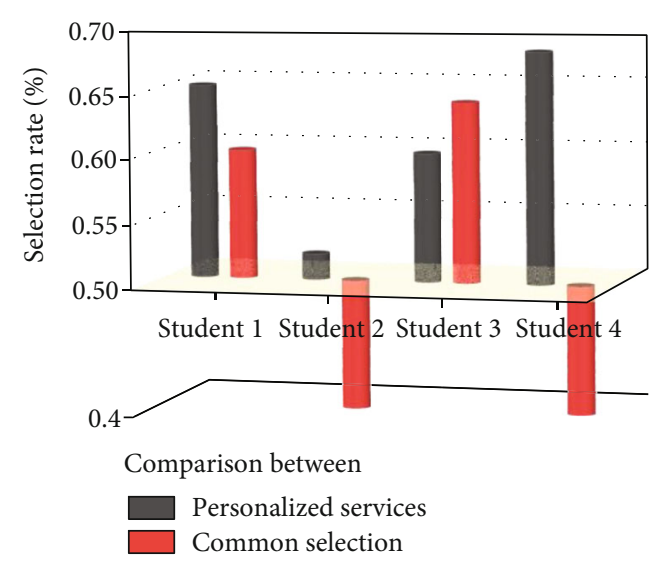

Figure 7: Degree of differentiation of personalized push.

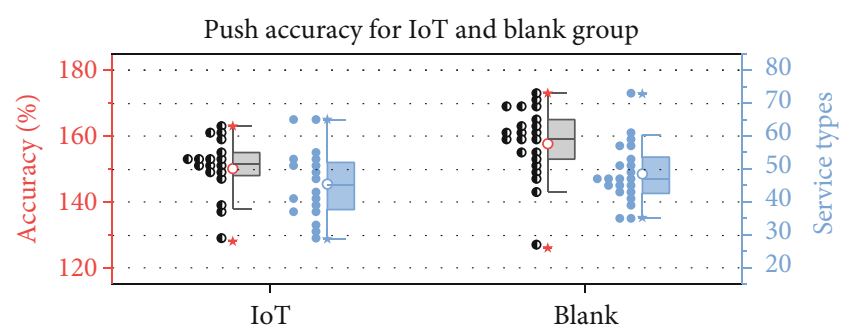

FIGURE 8: Comparison of push accuracy based on IoT technologies.

system was developed with a discipline-to-faculty correspondence table that gives users default disciplinary information based on their faculty backgrounds. If a reader does not set a subject preference when logging in to the information service system, the reader will receive the default subject library resources. If the reader has set his or her discipline preference, the system will push the book resources that are closer to the user's needs. The personalized recommendation service is made more valuable by setting your own special subject preferences based on your subject background, role information, etc.

The WeChat service provided by university libraries has many gaps from the real wisdom service, the content, means, ways, and planning of WeChat service are not perfect and mature, and it is still in the primary stage of exploration and experiment; university libraries should focus on relying on WeChat public platform to establish WeChat wisdom service. Under the micromedia environment, the wisdom WeChat service can expand the service scope, service content, and service mode of college libraries to better meet the different needs of different users. Traditional university libraries are often restricted by time or location, and for many readers who are not in the local service area or do not have computer terminals to access the Internet and during the nonworking hours of the library, the library does not provide basic services such as consultation and information sending. By using WeChat public service platform, university libraries can provide basic services to readers who have opened WeChat at anytime and anywhere and can also provide wisdom recommendation services for each different user to truly realize the wisdom service mode, as shown in Figure 8.
Library wisdom WeChat service, firstly, should provide basic services for all users including library search and lending query, secondly, provide RSS customization service, etc., to carry out new book notification, regular lecture information push, etc., and again, provide wisdom service, including providing differentiated recommendation for users, and by collecting and analyzing various information of users, providing users that may be interested in or have demand for at the same time, it provides intelligent consulting services, automatic answering services, and sets up WeChat message services, etc. to enhance the interaction and communication between the library and the users and to meet the real-time and diversified service needs of the users in time. Finally, a user sharing module can be set up to increase library users and make recommendations for friends through users' own evaluation or sharing of books, using social networks and other media technologies.

\section{Conclusion}

This paper investigates and analyzes the basic status of recommendation service in university libraries, combines quantitative and qualitative analysis, makes screening, classification, and integration of data, summarizes the service status and shortcomings of recommendation service in university libraries, presents the specific findings of recommendation service provided by domestic university libraries with charts and graphs, and after the data investigation and results display, finds that the service of recommendation system is much better than that of the system before optimization. In addition, this paper also provides a summary of the current situation and shortcomings of the recommendation services provided by domestic university libraries. In addition, this paper also puts forward the idea of constructing the wisdom library service model based on wisdom recommendation. The four aspects of wisdom retrieval, wisdom recommendation, wisdom APP, and wisdom micro media are discussed, and the contents, ways, and structures of wisdom services that should be provided by the four parts of wisdom service mode are analyzed in detail. Then, through the optimized and improved recommendation algorithm, information such as readers' personal subject knowledge background is incorporated into the readers' model, and the recommendation system is envisioned to be improved and constructed, and the applicable recommendation for colleges and universities is pointed out. The application algorithm of the service is pointed out.

\section{Data Availability}

The data used to support the findings of this study are available from the corresponding author upon request.

\section{Conflicts of Interest}

The authors declare that they have no known competing financial interests or personal relationships that could have appeared to influence the work reported in this paper. 


\section{References}

[1] Q.-G. Chen, L. Chen, Q.-H. Zhong et al., “Optimization of urinary small extracellular vesicle isolation protocols: implications in early diagnosis, stratification, treatment and prognosis of diseases in the era of personalized medicine," American Journal of Translational Research, vol. 12, no. 10, pp. 6302-6313, 2020.

[2] J.-N. Kramer, F. Künzler, V. Mishra et al., "Which components of a smartphone walking app help users to reach personalized step goals? Results from an optimization trial," Annals of Behavioral Medicine, vol. 54, no. 7, pp. 518-528, 2020.

[3] A. Kapusta, Z. Erickson, H. M. Clever et al., "Personalized collaborative plans for robot-assisted dressing via optimization and simulation," Autonomous Robots, vol. 43, no. 8, pp. 2183-2207, 2019.

[4] R. Logesh, V. Subramaniyaswamy, D. Malathi et al., "Dynamic particle swarm optimization for personalized recommender system based on electroencephalography feedback," Biomedical Research Tokyo, vol. 28, no. 13, pp. 5646-5650, 2017.

[5] P. S. Dulai and C. A. Siegel, "Optimization of drug safety profile in inflammatory bowel disease through a personalized approach," Current Drug Targets, vol. 19, no. 7, pp. 740-747, 2018.

[6] X. Wang, J. Zhou, W. Yang et al., "Warpage optimization and influence factors analysis of 3d printing personalized Jjy tablets," Drug Development and Industrial Pharmacy, vol. 46, no. 3, pp. 388-394, 2020.

[7] F. Mofidi and H. Akbari, "Personalized energy costs and productivity optimization in offices," Energy and Buildings, vol. 143, pp. 173-190, 2017.

[8] R. Alkurd, I. Y. Abualhaol, and H. Yanikomeroglu, "Personalized resource allocation in wireless networks: an Ai-enabled and big data-driven multi-objective optimization," IEEE Access, vol. 8, pp. 144592-144609, 2020.

[9] G. W. Colopy, S. J. Roberts, and D. A. Clifton, "Bayesian optimization of personalized models for patient vital-sign monitoring," IEEE Journal of Biomedical and Health Informatics, vol. 22, no. 2, pp. 301-310, 2018.

[10] M. E. Fresard, R. Erices, M. L. Bravo et al., "Multi-objective optimization for personalized prediction of venous thromboembolism in ovarian cancer patients," IEEE Journal of Biomedical and Health Informatics, vol. 24, no. 5, pp. 1500-1508, 2020.

[11] L. Xu, J. Zhang, B. Shi, and W. Meng, "Automating shiftscheduling calibration by using bionic optimization and personalized driver models," IEEE Transactions on Intelligent Transportation Systems, vol. 20, no. 12, pp. 4367-4376, 2019.

[12] Y. Zeng and R. Zhang, "Energy-efficient Uav communication with trajectory optimization," IEEE Transactions on Wireless Communications, vol. 16, no. 6, pp. 3747-3760, 2017.

[13] K. R. Devi and J. Bhavithra, "Personalized nutrition recommendation for diabetic patients using improved K-means and krill-herd optimization," International Journal of Scientific \& Technology Research, vol. 9, no. 3, pp. 1076-1083, 2020.

[14] D.-K. Lee, V. Y. Chang, T. Kee, C.-M. Ho, and D. Ho, "Optimizing combination therapy for acute lymphoblastic leukemia using a phenotypic personalized medicine digital health platform: retrospective optimization individualizes patient regimens to maximize efficacy and safety," Journal of Laboratory Automation, vol. 22, no. 3, pp. 276-288, 2017.
[15] Y. Gao, Y. Feng, and J. Tan, "Exploratory study on cognitive information gain modeling and optimization of personalized recommendations for knowledge reuse," Journal of Manufacturing Systems, vol. 43, pp. 400-408, 2017.

[16] W. Zhao, S. Li, H. Yao et al., "Molecular optimization enables over 13\% efficiency in organic solar cells," Journal of the American Chemical Society, vol. 139, no. 21, pp. 7148-7151, 2017.

[17] K. Cheng, Y. Liu, C. Yao, W. Zhao, and X. Xu, “A personalized mandibular implant with supporting and porous structures designed with topology optimization - a case study of canine," Rapid Prototyping Journal, vol. 25, no. 2, pp. 417-426, 2019. 